\title{
ELECTROCHEMICAL CHARACTERIZATION OF HIGH-PERFORMANCE SULFUR COMPOSITES AS CATHODES FOR Li-S BATTERIES WITH APPLICATION IN AUTOMOTIVE INDUSTRY
}

\begin{abstract}
Lithium-sulfur batteries are based on principle of conversion and their properties are very promising for their high theoretical energy density and low cost. However, current electrodes and materials used in Li-S batteries suffer from irreversible electrochemical reaction of polysulfides, low conductivity and stability. Here we summarize preparation and characterization of sulfur samples with polymer additive polypyrrole/polyethylene glycol to improve conductivity and stability of Li-S batteries. We also discuss very simple preparation technique of polypyrrole suitable also for industrial production. The electrochemical properties of sulfur-carbon-polypyrrole (S-C-PPy) composites were investigated by cyclic voltammetry $(\mathrm{CV})$, electrochemical impedance spectroscopy (EIS) and galvanostatic charge/discharge measurements. Properties of resulting composite samples (especially conductivity) are strongly affected by the preparation technique and conditions. Insulating polymer PEG was used to improve the polymeric structure and mechanical robustness of PPy chain. Porosity of composite sample increase with increasing amount of PPy. On the other hand conductivity is reduced with increased porosity. Electrochemical measurements confirmed that addition of PEG can improve conductivity also in the presence of higher amounts of PPy in the sample. PPy-PEG composite polymer decrease particle to particle contact resistance. Co-polymer coating consisting of PPy-PEG significantly decreases the charge transfer resistance of prepared samples what was confirmed by impedance measurements.
\end{abstract}

Keywords: lithium, sulfur, batteries, polypyrrole, conductivity

\section{Introduction}

Lithium-ion batteries (LIBs) are very important power sources since 1991. They can be used in many portable small electronic devices and electric vehicles due to the high capacity, long cycling and high energy density $[1,2]$. New cathode materials need to be developed and improved for high energy applications as electric vehicles. Sulfur is considered to be one of the most promising cathode for next-generation LIBs due to the high theoretical capacity (1672 mAh/g) [3], abundant reserves and nontoxic nature. However, a few drawbacks are related to Li-S battery practical application as low conductivity, volumetric changes, polysulfide shuttle mechanism or short life time. The theoretical capacity of sulfur coupled with the average operating voltage of a Li-S cell $\left(2.15 \mathrm{~V} v s ~ \mathrm{Li}^{+} / \mathrm{Li}^{0}\right)$ and the theoretical capacity of a pure lithium anode $(3862 \mathrm{mAh} / \mathrm{g}$ ) gives the energy density as high as $\sim 2500 \mathrm{Wh} / \mathrm{kg}$. Although Li-S batteries possess many advantages, low active material utilization, capacity degradation, self-discharge, poor Coulombic efficiency, poor cycle life, and electrode volume expansion are still the challenges remaining with the Li-S cells [4].

Electroactive conducting polymers (ECPs) are conjugated polymers that exhibit electronic conduction when partially oxidized or reduced and are capable of undergoing oxidation/ reduction reactions [5, 6]. Examples of ECPs include polypyrrole (PPy), polyaniline, polythiophene and polyphenylene vinylene. Several of these polymers have been tested as cathode materials for lithium batteries. Polypyrrole, for instance, can act as a host material for $\mathrm{Li}^{+}$-ion insertion/extraction in the voltage range of 2.0-4.5 V versus $\mathrm{Li} / \mathrm{Li}^{+}$, with a theoretical capacity of $72 \mathrm{mAh} / \mathrm{g}$ [7]. Therefore, PPy is a possible additive which can be used both as a conductive agent as well as a polymeric cathode material.

Herein, we report a simple preparation technique of sulfur$\mathrm{PPy} / \mathrm{PEG}$ composites with improved conductivity and stability.

\footnotetext{
* ${ }^{1}$ Andrea Strakova Fedorkova, ${ }^{1}$ Katarina Gavalierova, ${ }^{1}$ Dominika Capkova, ${ }^{2}$ Tomas Kazda

${ }^{1}$ Institute of Chemistry, Faculty of Science, P.J. Safarik University, Kosice, Slovakia

${ }^{2}$ Department of Electrical and Electronic Technology, Faculty of Electrical Engineering and Communication,

Brno University of Technology, Czech Republic

E-mail: andrea.fedorkova@upjs.sk
} 

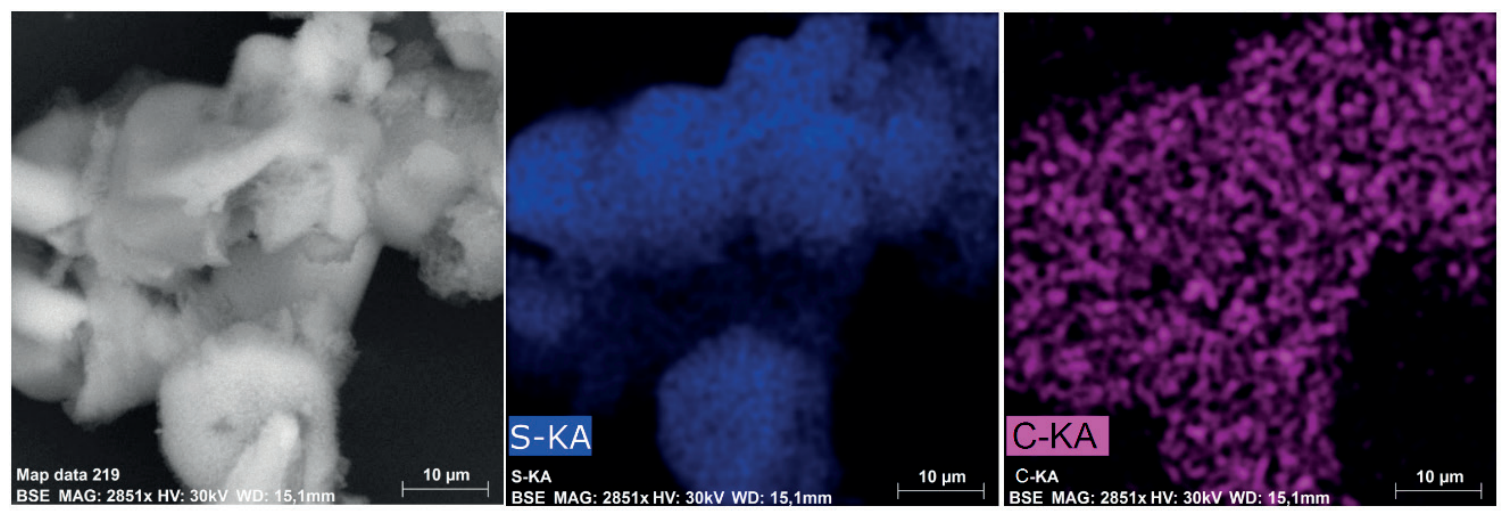

Figure 1 SEM image of S-C-PPy13\% composite sample and corresponding elemental maps for sulfur and carbon

Our aim is to produce composite samples with conductive polymer polypyrole to improve the conductivity and with higher porosity to accommodate insoluble polysulfides. Our results presents an effective approach to stabilize sulfur cathodes and obtain higher stability, efficiency and rate performance.

\section{Experimental}

\subsection{Preparation of polypyrrole and sulfur composites}

Polypyrrole was prepared by simple chemical oxidative polymerization in acid solution. $\mathrm{FeCl}_{3}$ was used as an oxidative agent. Temperature of polymerization was kept by the ice bath at a value $4{ }^{\circ} \mathrm{C}$. Sulfur-carbon-PPy composites were synthesized by heating the mixture of sulfur (Sigma-Aldrich), carbon Super $\mathrm{P}$ and PPy at $150{ }^{\circ} \mathrm{C}$ for 15 minutes. Sulfur at this temperature has low viscosity and can penetrate into the pores of polypyrrole and carbon. The weight ratio of PPy in composite sample was 5, 10, 13 and 15 wt. \%. Polyethylene glycol (PEG 600) (0.5 wt. \%) was added to sample with 13 wt. \% of PPy to improve the mechanical properties of the prepared composite.

\subsection{Preparation of cathodes and test cells}

Electrode slurries were made by mixing the sulfur composite as the active material with polyvinylidene fluorid (PVdF) in $\mathrm{N}$-methyl-2-pyrrolidone (NMP) with a weight ratio of 80:20. The slurry was then coated onto aluminium foil as current collector using the doctor-blade technique and subsequently dried in a vacuum oven at $60{ }^{\circ} \mathrm{C}$ for $18 \mathrm{~h}$. Circular electrodes with $18 \mathrm{~mm}$ diameter were cut out of the coated foil, with an area of 2.54 $\mathrm{cm}^{2}$ and total mass of $1.5-2 \mathrm{mg}$ on a substrate of $\mathrm{Al}$ foil. Three electrode test cells (ECC-STD El-Cell ${ }^{\odot}$ ) were assembled using these cathodes with lithium metal foil as counter and reference electrode and a fiber glass separator. All handling was done in an argon filled dry glove box (Jacomex, France). The electrolyte

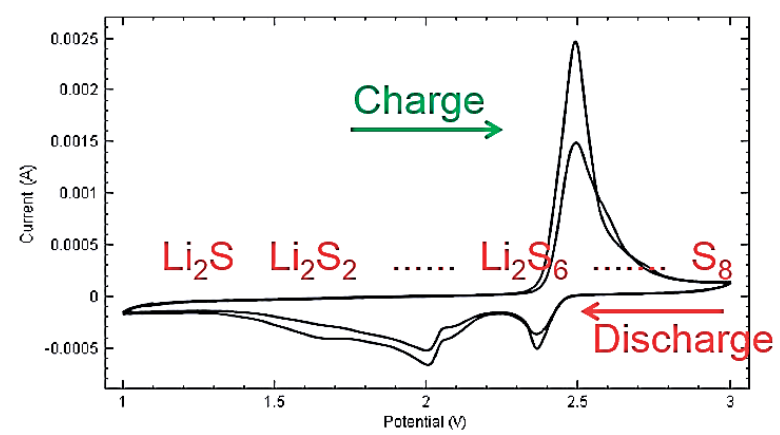

Figure 2 The cyclic voltammogram of S-C-PPy13\% composite sample at scan rate $0.1 \mathrm{mV} / \mathrm{s}$

used for all measurements consisted of $0.25 \mathrm{M} \mathrm{LiNO}_{3}$ and $0.7 \mathrm{M}$ LiTFSI dissolved in DME-DIOX (2:1).

\subsection{Sample characterization}

Galvanostatic charge/discharge measurements were performed within a potential window from 1.0 to $3.0 \mathrm{~V}_{\mathrm{vs} \text {. Li }}$ at different C-rates. CV curves were recorded in the potential window from 1.0 to $3.0 \mathrm{~V}_{\text {vs. Li. }}$, and the scan rate was set to $0.1 \mathrm{mV} / \mathrm{s}$. All electrochemical measurements were performed with Autolab potentiostat at room temperature. A typical sulfur mass loading on the electrode was $0.8-0.9 \mathrm{mg} / \mathrm{cm}^{2}$. Scanning electron microscope JEOL JSM-7000F + EDX INCA were used to observe the structure, morfology and composition of samples.

\section{Results and discussion}

Figure 1 shows the SEM image of S-C-PPy13\% composite cathode materials. We can see the porous agglomerated particles after polymerization of PPy. EDX elemental mapping confirmed homogeneous distribution of carbon, PPy and sulfur. Carbon and polymer composite created a continuous coating and sulfur 

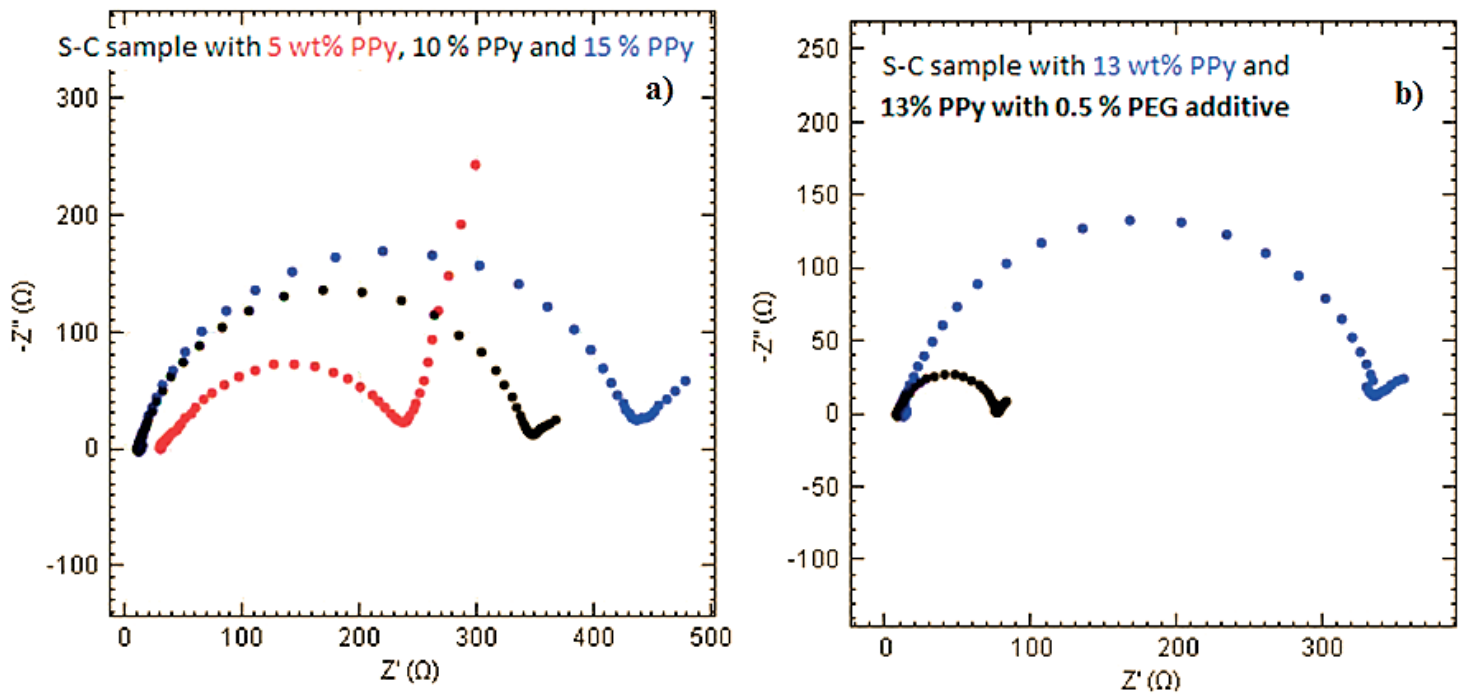

Figure 3 Nyquist plots of the a) S-C sample with $5 \mathrm{wt} . \%$ PPy (red), $10 \mathrm{wt} \%$ PPy (black), $15 \mathrm{wt}$ \% (blue) and b) S-C samples withMCWCS-S electrodes recorded at room temperature
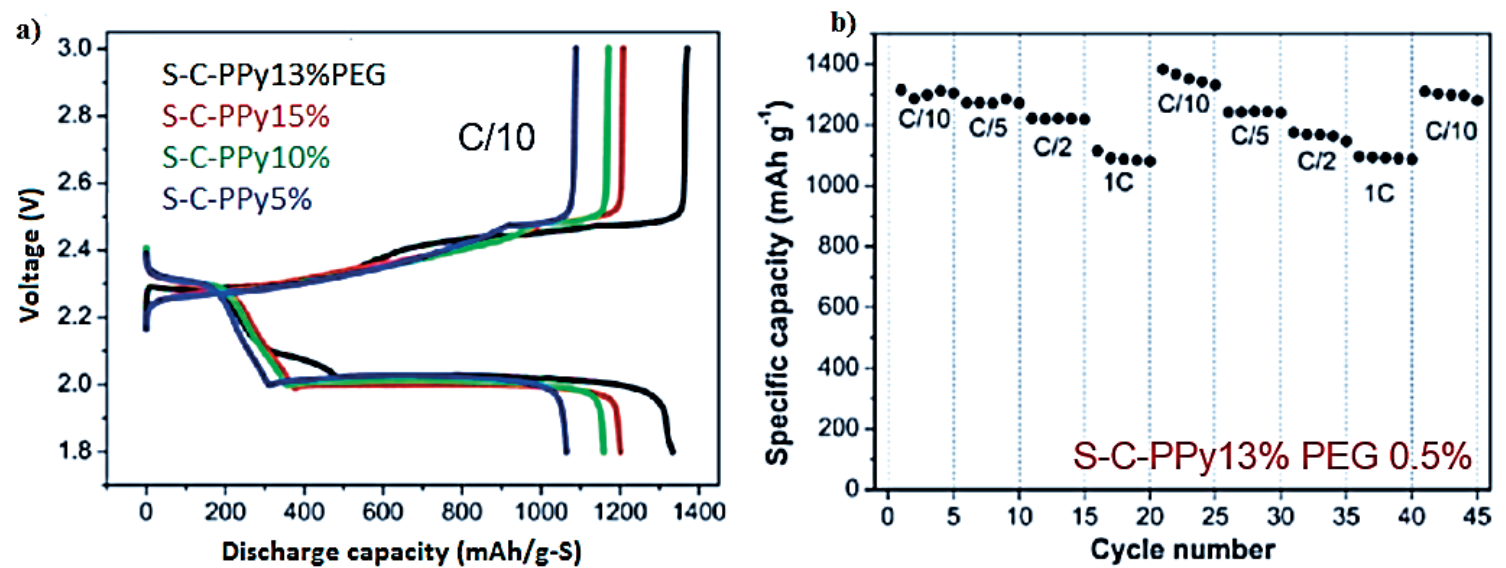

Figure 4 a) Galvanostatic charge-discharge profiles of the $S$-C samples with different amount of PPy at a $C$-rate of $0.1 C$ and $\boldsymbol{b}$ ) rate performance of the S-C-PPy $13 \% P E G 0.5 \%$ cathode at different C-rates

was accommodated in pores of carbon and polypyrrole. Smooth conductive layer can enhance the electron transfer and improve the total efficiency of Li-S battery.

Figure 2 shows the cyclic voltammograms (CV) of the composite electrode (S-C sample with 13 wt. \% of PPy and 0.5 wt. $\%$ of PEG) for the $1^{\text {st }}$ and $2^{\text {nd }}$ cycle. During the first reduction process (discharging), two typical peaks at 2.38 and $2.1 \mathrm{~V}$ are observed, corresponding to the reduction of elemental sulfur and to long-chain polysulfide $\left(\mathrm{Li}_{2} \mathrm{~S}_{\mathrm{n}}, \mathrm{n} \geq 8\right)$ and further to short-chain polysulfide (such as $\mathrm{Li}_{2} \mathrm{~S}_{6}, \mathrm{Li}_{2} \mathrm{~S}_{4}$ ) [8, 9]. In the subsequent anodic scan (charging), an intense, broader characteristic peak was observed at 2.5-2.6 V, reporting oxidation of sulfides to elemental sulfur. Anodic and cathodic current for the second cycle was decreased due to the partially irreversible reaction and formation of insoluble polysulfides.
The electrochemical impedance spectra (EIS) of different S-C-PPy samples at open circuit potential are shown in Figure 3 a, b. The charge-transfer resistance (Rct) of the S-C sample with 13 wt. \% of PPy and 0.5 wt. \% of PEG additive $(75 \Omega)$ is much smaller than that of the S-C-PPy sample without PEG additive $(330 \Omega)$. This result supports the hypothesis that the insulating polymer PEG improves electron and ion transport in the cathode and charge-transfer resistance of $\mathrm{Li}^{+}$ion is improved due to improved mechanical properties of PPy-PEG composite.

Galvanostatic charge/discharge measurements are shown in Figure 4 a, b. The S-C sample with 13 wt. \% of PPy and 0.5 wt. \% of PEG shows the faster electrochemical reaction with a smallest polarization compared with other samples. This result is in agreement with our previous EIS measurements. The highest discharge capacity observed for sample with PEG additive was $1325 \mathrm{mAh} / \mathrm{g}$-sulfur at a current density of $0.1 \mathrm{C}$. The discharge 
capacities of other samples are 1200, 1179 and $1068 \mathrm{mAh} / \mathrm{g}$ sulfur, respectively. These values can be compared with recently reported results for Li-S batteries [10-12].

The rate capability of the S-C sample with 13 wt. \% of PPy and 0.5 wt. \% of PEG electrode was investigated using a different C-rates. The discharge capacities of this electrode at $0.1 \mathrm{C}$, $0.2 \mathrm{C}, 0.5 \mathrm{C}$, and $1 \mathrm{C}$ after several cycles correspond to value of 1300, 1250, 1160 and $1100 \mathrm{mAh} / \mathrm{g}$-sulfur, respectively. Even at a higher C-rate, the S-C-PPy-PEG sample still presents a high specific capacity of $1100 \mathrm{mAh} / \mathrm{g}$-sulfur. When the rate returns back to $0.1 \mathrm{C}$, a specific capacity of $1300 \mathrm{mAh} / \mathrm{g}$-sulfur can still be obtained. This results indicates the excellent stability of S-CPPy-PEG composite sample. Improved PPy-PEG structure and increased porosity of resulting samples with sulfur can overcome polysulfides shuttling effect.

\section{Conclusions}

In conclusion, the S-C-PPy-PEG composites have been prepared by a simple oxidation polymerization reaction of Py monomere in acid solution and by evaporation of sulfur into the pores of carbon-polyppyrole composite matrix. To explore the effect of PPy-PEG additive, a series of samples with various content of PPy were investigated to optimize the electrode conductivity, porosity and performance. With increasing amount of PPy porosity was increasing but conductivity was decreasing. After optimization of composition between the sulfur, PPy and PEG a series of electrochemical measurements was performed. As the result, S-C sample with 13 wt. \% of PPy and 0.5 wt. \% of PEG delivers an optimal discharge capacity of $1300 \mathrm{mAh} / \mathrm{g}$-sulfur at $0.1 \mathrm{C}$ after 45 cycles, which owns to improved balance between two components. This material will indicate a new route to rationally design cathode materials for $\mathrm{Li}-\mathrm{S}$ batteries with superior stability and performance.

\section{Acknowledgement}

This research was sponsored by the NATO Science for Peace and Security Programme under grant 985148 and by the project VEGA 1/0074/17.

\section{References}

[1] SAGAR, R. U. R., MAHMOOD, N., STADlER, F. J., ANWAR, T., NAVALE, S.T., SHEHZAD, K., DU, B.: High Capacity Retention Anode Material for Lithium Ion Battery. Electrochimica Acta, 211, 156-163, 2016.

[2] HU, J. T., JIANG, Y., CUI, S. H., DUAN, Y. D., LIU, T. C., GUO, H., LIN, L. P., LIN, Y., ZHENG, J. X., AMINE, K., et al.: 3D-Printed Cathodes of LiMn1-xFexPO4 Nanocrystals Achieve Both Ultrahigh Rate and High Capacity for Advanced Lithium-Ion Battery. Advanced Energy Materials, 6(18), 1600856-1600868, 2016.

[3] Manthiram, A., Chung, S. H., Zu, C.: Lithium-Sulfur Batteries: Progress and Prospects. Advanced Materials, 25;27(12), 1980-2006, 2015.

[4] FEDORKOVA, A., ORINAKOVA, R., CECH, O., SEDLARIKOVA, M.: New Composite Cathode Materials for Li/S Batteries: A Review. International Journal of Electrochemical Science, 8, 10308-10319, 2013.

[5] TALlmAN, D. E., VANG, C., WALlACE, G. G., BIERWAGEN, G. P.: Direct Electrodeposition of Polypyrrole on Aluminum and Aluminum Alloy by Electron Transfer Mediation. Journal of the Electrochemical Society, 149(3), C173-C179, 2002.

[6] OSAKA, T., MOMMA, T., NISHIMURA, K., KAKUDA, S., ISHII, T.: Application of Solid Polymer Electrolyte to Lithium/ Polypyrrole Secondary Battery System. Journal of the Electrochemical Society, 141(8), 1994-1998, 1994.

[7] BRUCE, P. G., FREUNBERGER, S. A., HARDWICK, L. J., TARASCON, J.-M.: Li-O2 and Li-S Batteries with High Energy Storage. Nature Materials, 11(1), 19-29, 2012.

[8] FANG, X., LIU, S., ZANG, J., XU, C., ZHENG, M., DONG, Q., SUN, D., ZHENG, N.: Precisely Controlled ResorcinolFormaldehyde Resin Coating for Fabricating Core-Shell, Hollow, and Yolk-Shell Carbon Nanostructures. Nanoscale, 5, 69086916, 2013.

[9] DU, X., ZHANG, X., GUO, J., ZHAO, S., ZHANG, F.: Hierarchical Sulfur Confinement by Graphene Oxide Wrapped, WalnutLike Carbon Spheres for Cathode of Li-S Battery. Journal of Alloys and Compounds, 714, 311-317, 2017.

[10] CHEN, H., WANG, CH., DONG, W., LU, W., DU, Z., CHEN, L.: Monodispersed sulfur nanoparticles for lithium-sulfur batteries with theoretical performance. Nano Letters, 14;15(1):798-802, 2015.

[11] KAZDA, T., KRBAL, M., POUZAR, M., VONDRAK, J., STRAKOVA FEDORKOVA, A., SLAVIK, M., WAGNER, T., MACAK, J.: Highly Efficient and Stable Cryo-Ground Sulphur Cathode for Li-S batteries. Journal of Power Sources, 331, 293-298, 2016.

[12] KAZDA, T., CUDEK, P., VONDRAK, J., SEDLARIKOVA, M., TICHY, J., SLAVIK, M., FAFILEK, G., CECH, O.: LithiumSulphur Batteries Based on Biological 3D Structures. Journal of Solid State Electrochemistry, 1-10, 2017. https://doi.org/10.1007/ s 10008-017-3791-0. 